\title{
DIDÁTICA COMUNICATIVA E INTERAÇÃO SOCIAL: FUNDAMENTOS TEÓRICOS PARA PRÁTICAS EMANCIPATÓRIAS DA EDUCAÇÃO FÍSICA ESCOLAR
}

\author{
Juliano Daniel Boscatto \\ Universidade Federal de Santa Catarina, Florianópolis, Santa Catarina, Brasil \\ Elenor Kunz \\ Universidade Federal de Santa Catarina, Florianópolis, Santa Catarina, Brasil
}

\begin{abstract}
Resumo
Na compreensão da Educação Física como uma prática pedagógica, esse ensaio objetiva apresentar elementos teórico-pedagógicos para a Educação Física Escolar a partir de estudos que possam fundamentar uma didática comunicativa. Fundamenta-se metodologicamente nos pilares de uma pesquisa teórica centrada em estudos que tratam da emancipação humana. Apresenta-se a interação social, alicerçada em proposições teóricas com princípios voltados a uma pedagogia da comunicação e o diálogo intersubjetivo no decorrer das ações pedagógicas é imprescindível. Por meio da comunicação intersubjetiva, nos processos de ensinar e aprender, pode-se desencadear competências sociais, como o respeito, a solidariedade, a lealdade, a cooperação, imprescindíveis para a sociedade contemporânea.

Palavras-chave: Educação Física. Didática. Emancipação.
\end{abstract}

\section{Considerações iniciais}

$\mathrm{H}$ istoricamente, a produção do conhecimento no campo da Educação Física mantém uma relação estreita com as ciências da vida, buscando-se investigar de forma fragmentada, conforme o modelo científico normal de Kuhn (2003), padrões que estimam objetivamente aspectos relacionados ao desenvolvimento motor. Mais recentemente, surgiram estudos tendendo para a promoção de saúde. Paralelamente a esse cenário, cresce quantativamente o número de periódicos, segundo Dias e Silva (2010) e, com isso, aumenta também a produção de artigos que impulsionam o "inchaço" da plataforma lattes.

Como consequência, denominam-se determinadas abordagens para o ensino da educação escolar (DARIDO, 1999), que oferecem pressupostos teórico-metodológicos no sentido de legitimar a práxis educativa da Educação Física na escola. Abordagens que teoricamente 
poderiam dar suporte teórico-metodológico para o ensino da Educação Física, mas que, por muitas vezes, permanecem distantes do "chão da escola" por não serem discutidas e apropriadas pelos professores que fazem o dia a dia escolar.

Considera-se a Educação Física na perspectiva de prática pedagógica, que atribui sempre uma intencionalidade em suas ações educativas, pois todo o educar se faz como ação proposital de um grupo humano sobre si mesmo e sobre sua continuidade por meio de novas gerações (MARQUES, 1996). Para contribuir com processos de ensinar e aprender sob princípios da emancipação humana, torna-se necessário resgatar os fundamentos de uma educação comprometida realmente com os seres humanos, considerando que ela pode estar embasada na racionalidade comunicativa.

Neste ensaio, objetiva-se, portanto, apresentar elementos teóricopedagógicos ${ }^{1}$ para a Educação Física Escolar em estudos que possam fundamentar uma didática comunicativa.

Entre os fundamentos apresentados na sequência identificou-se um importante eixo denominado de interação social, sobre o qual pode-se contribuir com a ampliação de uma prática da Educação Física baseada em aspectos instrumentais. Partindo desses pressupostos, a construção e elaboração dos conhecimentos e a formação dos sujeitos por meio das práticas pedagógicas apresenta um caráter mais rico, pois podem possibilitar aos educandos o desenvolvimento de atitudes e valores que contribuem para o esclarecimento quanto às condições do contexto socioeconômico e cultural no qual os educandos estão inseridos.

\section{Procedimentos metodológicos}

Este estudo apresenta um fragmento de uma pesquisa teórica que aproximou as reflexões sobre os pressupostos teóricos e metodológicos direcionados para uma didática comunicativa no ensino da Edu-

1-Torna-se importante assinalar que este estudo traz como "pano de fundo" o paradigma da razão comunicativa de Habermas (1987), entretanto, por centrar atenção em questões que tratam especificamente do âmbito didático e pedagógico da Educação Física, a intenção é ampliar as questões filosóficas apresentadas por esse autor para o contexto da educação/Educação Física, não deixando de considerar os pressupostos de uma concepção comprometida com a emancipação humana.

Pensar a Prática, Goiânia, v. 15, n. 4, p. 821-1113, out./dez. 2012 
cação Física escolar. Para isso, foram considerados os pressupostos de um trabalho de cunho qualitativo que Nardi e Santos (2003, p. 55) descrevem: "o propósito fundamental da pesquisa qualitativa é a compreensão, exploração e especificação do fenômeno social". Assim, considera-se, neste espaço, a práxis educativa como um fenômeno de intervenção social que apresenta algumas especificidades, necessitando de discussão e aprofundamento teórico.

Reconhece-se que a pesquisa teórica pode estar intimamente ligada a questões da prática educativa, fornecendo-lhe subsídios consistentes para sua intervenção. Nesse sentido, pretendeu-se aproximar as questões que a compilação teórica apresenta, com o âmbito de intervenção prática, não deixando de considerar, sobretudo, o foco de interesse deste estudo, ou seja, subsidiar elementos teóricos para uma didática comunicativa.

Esta pesquisa apresenta a fundamentação metodológica baseada nos pilares de uma pesquisa teórica, na qual Demo (2004, p. 35) assinala: "pesquisa teórica, orientada para a (re)construção de teorias, quadros de referência, condições explicativas da realidade, polêmicas e discussões pertinentes. [...] Seu papel é para construir condições básicas de intervenção, precisamente o investimento em conhecimento como instrumento principal de intervenção competente".

A partir das compilações teóricas discutidas nesse estudo, pretendeu-se elaborar elementos para uma didática comunicativa no campo pedagógico da Educação Física. Entre esses elementos, destaca-se a categoria da interação social como um importante fundamento para práticas educativas emancipatórias.

\section{Didática comunicativa e interação social}

Preliminarmente, torna-se importante ressaltar que as considerações, postas neste espaço, estão centradas na perspectiva de contribuir para o processo da emancipação humana. Esse processo pode acontecer em uma "relação de tensão permanente", que envolve a formação de identidades dos sujeitos e, paralelamente a isso, a constituição da sociedade, ou, dito de outro modo, o processo de emancipação pode ocorrer em meio às diferentes expressões subjetivas, pulsões, desejos, ansiedades, etc. Essas expressões exercem uma inter-relação com os demais seres humanos, com o mundo e com a natureza. Considera-se essa questão essencial, pois a concretização de práticas de ensino cen- 
tradas em pressupostos emancipatórios não pode ser atribuída apenas a uma disciplina que compõe a grade curricular (KUNZ, 2004a).

Acrescenta-se, então, que, a partir dessa "relação de tensão permanente" entre os interesses individuais (fator subjetivo) e os padrões constituídos historicamente pela sociedade (fator social), são formadas as "identidades" pessoais. Habermas (1983, p. 54, grifo do autor) assinala:

A identidade de Eu depende naturalmente de determinadas premissas cognoscitivas, mas não é uma determinação do Eu epistêmico, constituindo-se antes numa competência que se forma em interações sociais. A identidade é gerada pela socialização, ou seja, vai se processando a medida que o sujeito - apropriando-se dos universos simbólicos - integra-se, antes de mais nada, num certo sistema social, ao passo que, mais tarde, ela é garantida e desenvolvida pela individualização, ou seja, precisamente por uma crescente independência com relação aos sistemas sociais.

Considerando esses elementos, pode-se afirmar que, na sociedade contemporânea, existem inúmeras instituições que promovem essa relação tensa na formação de identidades. Para a discussão a que se propõe este estudo, é necessário considerar que a instituição social denominada "escola" pode apresentar-se como um terreno "fértil" para o desenvolvimento de identidades com caráter emancipatório. Para tanto, é fundamental que, além de desenvolver a sua tradicional atribuição de transmitir os saberes acumulados historicamente, é necessário que ela contribua com a formação de competências sociais ${ }^{2}$ entre os sujeitos (BAECKER, 2000, 2004).

Apresenta-se, então, um importante elemento para a didática comunicativa em aulas de Educação Física, a interação social. Visualizase nas práticas de ensino da Educação Física um ambiente "rico" em interações sociais pela característica dinâmica em que as experiências

2-Baecker (2000, p.131) utiliza o termo "competências para o agir social" correspondente à designação para a capacidade de ação a ser adquirida pelo sujeito de forma a atuar como indivíduo social dentro de uma realidade específica. Para isso, o ser humano, no decorrer de sua vida, terá que adquirir saberes, conhecimentos, regras, normas, valores para poder atuar em contextos de interações reais, equilibrando-se necessidades e expectativas individuais e sociais. 
de movimento manifestam-se. Por meio de práticas corporais, podem ser demonstrados vários elementos que envolvem interações sociais, como: as comparações entre os sujeitos (eu consigo chutar a bola mais longe que meu colega), as diferentes formas de comunicação (verbal, gestual), as manifestações culturais (danças, cantigas de roda), entre outras. Utilizando-se do aspecto da interação social, há possibilidade de desenvolver práticas de ensino fundadas em ações comunicativas e, acerca desse assunto, Market (2004, p. 151) acrescenta que "Habermas vincula esta ação, na sua idealidade, às implicações emancipatórias das relações comunicativas, que possam gerar interações individuais não submissas à lógica instrumental e ao poder social".

A interação social, no âmbito de uma didática comunicativa, deve estar fundamentada em proposições teóricas que apresentem princípios centrados em uma pedagogia da comunicação e, com isso, o diálogo intersubjetivo no decorrer das ações pedagógicas é imprescindível. Dessa forma, Freire (1983, p. 83) destaca que "somente o diálogo, que implica um pensar crítico, é capaz de também gerá-lo. Sem ele não há comunicação e sem esta não há verdadeira educação". Torna-se importante superar a relação monológica e instrumental nos processos de ensinar e aprender em aulas de Educação Física para uma perspectiva que busque na comunicação recíproca elementos que conduzam para a formação das competências sociais.

Isso significa ir além das expectativas postas por instituições e de interesses promovidos pelo mundo dos sistemas, cujo objetivo é atingir o maior rendimento em todas as instâncias. Para isso, é necessário que as ações educativas sejam coordenadas por um parâmetro de racionalidade e de crítica, em que o sujeito deixa de ser aquele que se relaciona com os objetos, a fim de conhecê-los para manipulá-los, passando a ser a relação intersubjetiva, que os sujeitos entre si estabelecem com o propósito de se entenderem sobre algo (BOUFLEUER, 2001).

Em práticas da Educação Física escolar há inúmeras formas de se proporcionarem experiências de movimento, em que os sujeitos possam, pelas interações sociais, agir comunicativamente na construção das brincadeiras, dos jogos, esportes e dos outros elementos presentes na cultura de movimento. Para isto, Baecker (2000, p. 131) acrescenta que "a criança terá que ter chances de compreender o significado e o sentido da aula, de participar subjetivamente, considerando o desejo da maioria. Ela terá que equilibrar suas necessidades e vontades indi- 
viduais com as necessidades e vontades do coletivo", desenvolvendo, assim, as identidades pessoais.

Então, a criança e o adolescente começam a perceber que fazem parte de um grupo, de uma comunidade e da constituição das ações que ocorrem nesses grupos sociais. Caminha-se, dessa forma, na direção do que Habermas (2004, p. 13) apresenta: "nos permite conceber a comunidade abrangente que faz suas próprias leis, uma comunidade formada de indivíduos livres e iguais que se sentem obrigados a tratar uns aos outros como fins em si mesmos". Trata-se de iniciar um processo que busca romper com a tradição centrada em visões dicotômicas, que separam homem e mundo, sujeito e sociedade, sobretudo, permanecendo uma visão holística, em que as identidades constituemse mutuamente ao mesmo tempo em que produzem e reproduzem a cultura, a sociedade e o mundo.

Partindo desses princípios, torna-se fundamental, então, apresentar alguns pressupostos referentes às questões didático-metodológicas da Educação Física e, utilizando-se da "categoria" da interação social, pretende-se explicitar essas pressuposições mais detalhadamente, na sequência desta pesquisa.

\section{A interação social como pressuposição didático-metodológica}

Torna-se necessário apresentar alguns aspectos relacionados mais especificamente à práxis educativa, ou seja, gerar elementos que se relacionam diretamente com proposições didático-metodológicas em aulas de Educação Física escolar, contribuindo, assim, para sua legitimidade. Compreende-se que, nas relações com o movimento humano, uma didática comunicativa supera o caráter restritamente biológico/físico, para contemplar uma "totalidade", que envolve também os aspectos históricos, culturais, antropológicos. Kunz (2004a, p. 108) acrescenta que o "resgate dessa linguagem do movimento, que transcende o desenvolvimento da competência instrumental-objetiva, deverá trazer novos valores pedagógicos para a Educação Física e assim, auxiliar na difícil tarefa de legitimá-la enquanto prática pedagógica que contribui na formação da cidadania".

Para a elaboração de elementos referentes às ações didático-metodológicas, buscam-se alguns estudos de cunho teórico e empírico desenvolvidos por autores, entre os quais Baecker (2000, 2004), Kunz (2001), Vieira, Basei e Boscatto (2005), Funke-Wieneke (2006), que 
discutem algumas proposições para o ensino da Educação Física escolar centradas em princípios da emancipação humana.

Parte-se do pressuposto de que trata Hildebrandt-Stramann (2001, p. 47, grifo nosso): "Eu compreendo aula como um processo de interação social, no qual o professor e os alunos definem suas situações de ação e, com isso, determinam os seus significados". Em uma didática comunicativa, deve haver possibilidades de construção de conhecimentos a partir da relação intersubjetiva, o que, logicamente, significa que devem ser proporcionadas situações de ensino-aprendizagem que "provoquem" a interação social.

Entretanto, para a proposta em construção, aqui, não se pode considerar que todos os processos que envolvam a relação entre mais de um sujeito constituem uma interação social, no sentido de uma perspectiva emancipatória.

A interação social, na perspectiva proposta neste estudo, está vinculada ao que Bannell (2006, p. 53) descreve: "O que é importante notar, por enquanto, é que o agir comunicativo estabelece uma relação reflexiva com o mundo, na qual a pretensão de validade levantada em cada enunciado deve ser reconhecida intersubjetivamente; para isto acontecer, o falante depende da cooperação dos outros". Nesse sentido, há necessidade de promover ações comunicativas, em que os sujeitos possam agir de forma não coercitiva e com uma intencionalidade própria, com a finalidade de se entenderem em relação aos conteúdos de ensino estudados.

Assim, considera-se que a interação social deve ser tratada "pedagogicamente", ou seja, é um "tema" que deve ser organizado de forma intencional nas ações didático-metodológicas da Educação Física escolar ${ }^{3}$. Essa "intencionalidade pedagógica" está dirigida à formação de uma "identidade" (que é pessoal, porém constituída em "tensão" com a sociedade), autônoma, com vistas a uma atuação esclarecida na constituição da sociedade. Para tanto, é necessário proporcionar em práticas da Educação Física experiências de movimento que possibilitem "uma interação em que os sujeitos possam agir no mundo e com o mundo de forma emancipada. Dessa forma, o sujeito estará participando da construção de seu mundo, sendo necessário, então, adquirir competências sociais" (VIEIRA; BASEI; BOSCATTO 2005, p. 235).

3-Prestes (1996) assinala que a interação é o espaço onde se dão os conflitos entre pré-compreensão do mundo da vida e ação comunicativa. A estabilidade do mundo da vida é abalada pelos argumentos da ação comunicativa. 
Torna-se, pois, importante proporcionar por meio dos elementos da cultura de movimento, a interação social, com a finalidade de promover, também, algumas qualificações básicas para os sujeitos agirem socialmente. Acerca do assunto, Funke-Wieneke (2006), apoiado em Krappmann (1988), assinala para a necessidade de proporcionar algumas situações de práticas corporais que favoreçam os sujeitos nas seguintes situações:

1. assumir papéis: refere-se à capacidade de se colocar no lugar do outro e de reconhecer as expectativas dos parceiros, ou seja, ver a situação que um colega se encontra na interação;

2. manter distância em relação aos papéis: ter a capacidade de se comportar de forma reflexiva e interpretativa diante das normas e expectativas sociais. Relacionar e confrontar, dialogicamente, desejos e expectativas que os respectivos parceiros da interação têm das minhas condutas com os meus próprios desejos e expectativas, bem como com os valores e normas sociais;

3. tolerância à ambiguidade: saber suportar, apesar das satisfações garantidas nas interações, os acontecimentos indesejáveis que, paralelamente, ocorrem. Saber questionar expectativas contraditórias e dar continuidade às interações sociais, mesmo que elas não satisfaçam, plenamente, os seus próprios desejos e expectativas;

4. apresentação de identidade: introduzir sua própria identidade nos processos interacionais, ou seja, apresentar sua identidade. Dar a conhecer aos parceiros das interações seus próprios desejos e expectativas e não apenas assumir as expectativas dos outros.

Percebe-se que a possibilidade de promover as qualificações sociais, citadas acima, não está centrada exclusivamente na dimensão substancial (SCHALLER; SCHÄFER, 1982), ou seja, detida (apenas) em conceitos abstratos, em regras desportivas, em fatos históricos ou no entendimento dos processos fisiológicos corporais, etc. Sobretudo em uma didática comunicativa, é de fundamental importância a "forma" (dimensão relacional) de como se transmitem os conteúdos de ensino nos processos de ensinar e aprender e, nesse sentido, apresenta-se a pedagogia da comunicação ${ }^{4}$, em que os atores do processo educativo tomam o conteúdo como objeto de estudo, a fim de aferi-

\footnotetext{
4-Schaller e Schäfer (1982) assinalam que o próprio processo de comunicação contém um elemento educativo e que, na educação, o jovem deve receber uma "orientação" para sua atuação presente e futura, desde que o processo de comunicação ocorra em "sistemas abertos (quer dizer, transformáveis)".
}

Pensar a Prática, Goiânia, v. 15, n. 4, p. 821-1113, out./dez. 2012 
rem pretensões de validade provisórias e a consequente produção do conhecimento.

Em interações sociais, é de fundamental importância o diálogo intersubjetivo, o qual contribui com a reformulação dos saberes acumulados e sistematizados historicamente, ao serem problematizados com as especificidades do contexto em que os sujeitos se inserem. Assim sendo, Freire (1983, p. 79) reforça que:

Por isto o diálogo é uma exigência existencial. E, se ele é o encontro em que se solidarizam o refletir e o agir de seus sujeitos endereçados ao mundo a ser transformado e humanizado, não pode reduzir-se a um ato de depositar idéias de um sujeito no outro, nem tampouco tornar-se simples troca de idéias a serem consumidas pelos permutantes.

A não reprodução mecânica dos conteúdos de ensino contribui para a formação de identidades não submissas aos ditames postos pelo mundo do sistema. Não raro, a mídia, por meio da televisão, revistas ou jornais, perpetua e idealiza inúmeros "modelos perfeitos". Dentre eles, destacam-se os padrões corporais ou "esculturais" esteticamente ${ }^{5}$, os exemplos de (dadas as devidas proporções, uma pequena minoria de) atletas que obtêm a "superação" socioeconômica precária por intermédio do esporte, as regras ou "dicas" que mantêm a saúde e a "qualidade de vida" dos sujeitos, entre outros. Todos esses esteriótipos, difundidos por uma massa que busca formar desejos e necessidades nos consumidores, podem ser refletidos, problematizados em práticas da Educação Física Escolar, com a finalidade de contribuir para a formação de identidades pessoais esclarecidas. Esse processo pode ocorrer a partir de procedimentos didático-metodológicos, que preconizem a interação social, questionando e colocando em "xeque" as informações postas como verdades absolutas. Acerca desse assunto, Boufleuer (2001, p. 76) acrescenta: "Visto como produto de uma relação argumentativa entre sujeitos, o conhecimento, em sua concepção argumentativa, acentua, sobretudo, o caráter histórico da educação e dos saberes por ela veiculados".

Entende-se que essa historicidade do processo educacional, desenvolvida no contexto da educação formal como uma possibilidade de

5-Estética aqui refere-se, restritamente, ao belo.

Pensar a Prática, Goiânia, v. 15, n. 4, p. 821-1113, out./dez. 2012 1038 
superar as tradicionais práticas da Educação Física, centrada no rendimento técnico-desportivo (que, por seus princípios, ocasionam a exclusão dos sujeitos que não possuem a habilidade exigida) e, também, oferece a oportunidade de propor alternativas pedagógicas que possam contribuir para a superação da "crise de legitimidade"6, presente em alguns contextos escolares.

Apresenta-se, então, a necessidade de proporcionar alguns fundamentos teóricos para as ações didático-metodológicas que promovam o desenvolvimento de competências sociais e, com isso, contribuir para a legitimidade da Educação Física enquanto prática pedagógica. É o que pretende-se apresentar na sequência.

\section{Considerações finais}

Pelo fato de este ensaio se tratar de fundamentos teórico-metodológicos centrados em elementos críticos, com base na emancipação humana, faz-se necessário, desse modo, compreender as estruturas que remetem ao processo emancipatório, atendendo às especificidades da era contemporânea. Nesse sentido, constata-se que, para o referido processo, torna-se importante considerar principalmente dois aspectos: a razão e a linguagem. Essas estruturas podem contribuir com a compreensão crítica das composições tecnocráticas que regem o sistema socioeconômico e cultural.

Para a era atual, o desenvolvimento da reflexão crítica não está, de forma alguma, direcionado para um sujeito apenas, sendo, sobretudo, constituída dialogicamente, tornando-se necessário, então, a estrutura da "linguagem" intersubjetiva para compreensão do mundo do sistema e para a superação do paradigma da razão instrumental. Conclui-se, portanto, que o processo emancipatório envolve dois momentos concomitantes: adaptação e resistência crítica (esclarecimento das condicionantes sociais), formuladas dialogicamente entre os sujeitos, sendo que, a "adaptação não deve conduzir a perda da individualidade em um conformismo uniformizador" (ADORNO, 1995, 144).

6-Kunz (2006, p. 15) assinala que, após um número significativo de estudos no campo da pedagogia da Educação Física, entre os quais o autor destaca os trabalhos de Bracht, Betti, Tafarel, etc., "o profissional de Educação Física em geral cumpre um programa de acordo com sua qualificação no esporte, suas preferências e gostos e, até mesmo, com seu humor do dia". 
Para as práticas educativas da Educação Física, é importante considerar dois elementos que formam a comunicação: o diálogo verbal, considerado um importante aspecto para a ação comunicativa, que permite a reflexão crítica sobre as ações de movimento, demais "conflitos", formas de interação que ocorrem nas práticas de ensino; e o diálogo corporal, ou seja, o próprio movimento humano manifestando-se de forma pré-reflexiva como expressão subjetiva, que transmite um sentido e significado próprio na ação. Nesses termos, apresentamse, para didática comunicativa, duas perspectivas epistemológicas distintas: o agir comunicativo/ação comunicativa e a concepção dialógica do movimento.

Tomando como "pano de fundo" essas fundamentações teóricas, podem ser proporcionadas, em aulas de Educação Física, situações didático-metodológicas, por meio da interação social, a fim de contribuir para a formação de identidades pessoais não submissas aos ditames do sistema socioconômico excludente. Considera-se a afirmação de Kunz (2007, p. 95): "o ser humano é um ser social e cultural, porque somos formados não apenas por uma identidade individual, ou seja, somos como ninguém é, mas, essencialmente, somos uma identidade social e cultural, ou seja, somos como todo mundo é". Em meio às relações sociais ocorridas no contexto escolar e, especialmente, em aulas de Educação Física, pode-se auxiliar com o desenvolvimento de identidades emancipadas.

Identificar-se como um sujeito histórico e, com isso, construtor da própria sociedade, na qual está inserido, induz à compreensão de que há possibilidades de se re-significarem, também, algumas práticas da Educação Física Escolar que carecem de legitimidade pedagógica. Essa legitimidade pode estar vinculada a pressupostos teórico-metodológicos centrados em uma forma de pensar, refletir e agir mantida sob base da reciprocidade de sujeitos capazes de se comunicar com os outros. Possivelmente, pelo desenvolvimento da comunicação intersubjetiva, nos processos de ensinar e aprender pode-se desencadear competências sociais e valores humanos, como o respeito, a solidariedade, a lealdade, a cooperação, imprescindíveis para a atual sociedade. 
Teaching communicative and social interaction: theoretical foundations for emancipatory practice of physical education

\begin{abstract}
In the understanding of physical education as a pedagogical practice, this essay aims to present theoretical and pedagogical elements for physical education from studies that may support a communicative teaching. It is based methodologically on the pillars of a theory-driven research studies dealing with human emancipation. It presents social interaction, based on theoretical propositions with a teachingcentered principles of communication and dialogue during the intersubjective pedagogical actions is essential. By means of intersubjective communication, the processes of teaching and learning can trigger social skills such as respect, solidarity, loyalty, cooperation, vital to contemporary society.
\end{abstract}

Keywords: Physical Education. Didactics. Emancipation.

La enseñanza de interacción comunicativa y social: fundamentos teóricos para la práctica emancipatoria de la educación física

\title{
Resumen
}

En la comprensión de la educación física como práctica pedagógica, este ensayo tiene como objetivo presentar los elementos teóricos y pedagógicos de la educación física de los estudios que pueden apoyar una enseñanza comunicativa. Se basa metodológicamente en los pilares de un estudio de investigación conducido la teoría-se ocupan de la emancipación humana. Se presenta la interacción social, con base en propuestas teóricas con una enseñanza centrada en los principios de la comunicación y el diálogo en las acciones pedagógicas intersubjetivo es esencial. Por medio de la comunicación intersubjetiva, los procesos de enseñanza y aprendizaje pueden desencadenar las habilidades sociales como el respeto, la solidaridad, la lealtad, la cooperación, vital para la sociedad contemporánea.

Palabras clave: Educación Física. Didáctica. La emancipación.

Referências

ADORNO, T. Educação e emancipação. 3. ed. São Paulo: Paz e Terra, 1995.

BAECKER, I. M. O desenvolvimento de competências sociais em aulas de Educação Física. Cinergis, Santa Cruz do Sul, v. 1, n.1, p. 127-138. 2000.

. O desenvolvimento das crianças e jovens pelo movimento: quais são as perspectivas resultantes do desenvolvimento pelo movimento, para a formação dos professores de Educação Física brasileiros?. In: KUNZ, E. HILDEBRANDT-STRAMANN, R. Intecambios 
científicos internacionais em Educação Física. Ijuí, Unijuí, 2004. p. 179-200.

BANNELL, R. I. Habermas e educação. Belo Horizonte: Autentica, 2006.

BOUfLEUER, P. J. Pedagogia da ação comunicativa. 3. ed. Ijuí: Unijuí, 2001.

DARIDO, S. C. Educação Física na escola: questões e reflexões. Araras: Topázio, 1999.

DEMO, P. Pesquisa e construção de conhecimento: metodologia científica no caminho de Habermas. Rio de Janeiro: Tempo Brasileiro, 2004.

DIAS, C.; SILVA, A. M. Quando Menos É Mais: Política Editorial e o Fetichismo dos Números. Pensar a Prática, Goiânia, v. 14, n. 1, p. 111, jan./abr. 2010.

FREIRE, P. Pedagogia do Oprimido. 14. ed. Rio de Janeiro: Paz e Terra, 1983.

FUNKE-WIENEKE, J. O que dizer sobre "aprendizagem social" no ensino de movimentos e na Educação Física, e o que podemos alcançar com ela. In: KUNZ, E.; TREBELS, A. H. Educação Física crítico-emancipatória: com uma perspectiva alemã do esporte. Ijuí: Unijuí, 2006. p. 49-74.

HABERMAS. Para a reconstrução do materialismo histórico. São Paulo: Brasiliense, 1983.

. Teoria de la acción comunicativa. Madrid: Taurus, 1987.

. A ética da discussão e a questão da verdade. São Paulo: Martins Fontes, 2004.

HILDEBRANDT-STRAMANN, R. Textos pedagógicos sobre o Ensino da Educação Física. Ijuí: Unijuí, 2001.

KUHN, T. S. A Estrutura das Revoluções Científicas. 7. ed. São Paulo: Perspectiva, 2003. 
KUNZ, E. Didática da Educação Física 1. 2. ed. Ijuí: Unijuí, 2001.

. Transformação didático: pedagógica do esporte. 6. ed. Ijuí: Unijuí, 2004a.

. Pedagogia do esporte, do movimento humano ou da Educação Física? In: KUNZ, E.; TREBELS, A. H. Educação Física críticoemancipatória: com uma perspectiva alemã do esporte. Ijuí: Unijuí, 2006.

Ciências do esporte da Educação Física e do movimento humano: prioridades, privilégios e perspectivas. In: CARVALHO, Y. M.; LINHALES, M. A. Política científica e produção do conhecimento em Educação Física. Goiânia: Colégio Brasileiro de Ciências do Esporte, 2007.

MARKET, W. Trabalho, comunicação e competência: contribuições para a construção crítica de um conceito e para a formação do profissional transformativo. Campinas: Autores Associados, 2004.

MARQUES, M. O. Educação/Interlocução, aprendizagem/reconstrução de saberes. Ijuí: Unijuí, 1996.

NARDI, E. L.; SANTOS, R. dos. Pesquisa teoria e prática. Porto Alegre: Est. Edições, 2003.

PRESTES, N. H. Educação e racionalidade: conexões e possibilidades de uma razão comunicativa na escola. Porto Alegre: Edipucrs, 1996.

SCHALLER, K.; SCHÄFER, K. Ciência educadora crítica e didática comunicativa. Rio de Janeiro: Tempo Brasileiro, 1982.

VIEIRA, M. A.; BASEI, A. P.; BOSCATTO, J. D. "Se-movimentar": uma proposta para aulas de Educação Física. Visão Global, São Miguel do Oeste, v. 8, n. 30, p. 220-242, jul./dez. 2005.

Recebido em: 21/07/2011

Revisado em: 10/11/2011

Aprovado em: 04/02/2012

Pensar a Prática, Goiânia, v. 15, n. 4, p. 821-1113, out./dez. 2012 1043 


\section{Endereço para correspondência}

kunz@cds.ufsc.br

Elenor Kunz

Universidade Federal de Santa Catarina

Centro de Desportos, Departamento de Educação Física.

CDS-UFSC

TRINDADE

88040-900 - Florianopolis, SC - Brasil 